\title{
REESCRITURAS DE ANTÍGONA E FACES MODERNAS DO TRÁGICO ${ }^{1}$ THE REWRITINGS OF ANTIGONE AND THE MODERN FACES OF TRAGIC
}

\author{
Sonia Aparecida Vido Pascolati (UEL) ${ }^{2}$ \\ sopasco@hotmail.com
}

\begin{abstract}
RESUMO: Em meio ao desenrolar da Segunda Guerra Mundial e pouco após o seu fim, dois dramaturgos resgatam o mito de Antígona celebrizado pelo texto clássico de Sófocles, redesenhando o perfil da heroína e reescrevendo as motivações e o desenvolvimento da ação dramática. Jean Anouilh, adotando a perspectiva da Resistência francesa à ocupação alemã, cria em Antigone (1942) uma personagem obstinada em defender um ideal de pureza quando os demais estão dispostos a transigir em nome da manutenção da ordem. O alemão Bertolt Brecht denuncia direta e profundamente as motivações econômicas da guerra de Hitler, colocando a protagonista de A Antígona de Sófocles (1948) em franca oposição a um Creonte que claramente remete ao insano ditador alemão. As reescrituras do texto sofocliano não só emprestam novos contornos a Antígona, como também provocam uma reflexão instigante quanto ao lugar do trágico e da tragédia no mundo moderno assolado pela guerra. As novas faces de Antígona delineadas em Antigone e A Antígona de Sófocles são também novas faces do trágico, possíveis pela recontextualização do mito clássico. Portanto, neste trabalho, pretendo apontar algumas dessas novas faces surgidas a partir do resgate de uma figura mitológica em tempos de destruição da humanidade e do humano.
\end{abstract}

PALAVRAS-CHAVE: tragédia; trágico; Antígona; Sófocles; Jean Anouilh; Bertolt Brecht.

ABSTRACT: Amid the development of Second World War and shortly after its end, two playwrights recover the famous myth of Antigone, celebrated by the Sophocles's classic text, redesigning the heroine's profile and rewriting the motivations and development of the dramatic action. Jean Anouilh, adopting the perspective of the French resistance to German occupation, creates in Antigone (1942) a character driven to defend an ideal of purity when all others are willing to give in the name of order maintenance. The German playwright, Bertolt Brecht candidly and deeply exposes the economic motivations of Hitler's war, putting the protagonist of Antigone of Sophocles (1948) in forthright opposition to a Creonte who clearly refers to the mad German dictator. The rewritings of Sophocle's text not only lend new contours to Antigone, but also causes an instigating discussion about the place of the tragic and the tragedy in the modern world devastated by war. The new faces of Antigone, outlined in Antigone and Antigone of Sophocles are also new faces of the tragic, possible by the recontextualization of the classical myth. Therefore, in this work, I intend to point out some of these new faces emerged from the rescue of a mythological figure in times of both human and humanity destruction.

KEY WORDS: tragedy; tragic; Antigone; Sophocles; Jean Anouilh; Bertolt Brecht.

\section{Introdução}

O conceito, a noção e mesmo a idéia de trágico ocupam um lugar de destaque e têm sido objeto de reflexão nas mais diferentes áreas do saber, em particular nos estudos literários; entretanto, isso não tem garantido uma clareza quanto à aplicação ou

\footnotetext{
${ }^{1}$ As reflexões aqui apresentadas resultam de pesquisa em nível de doutorado desenvolvida no Programa de Pós-Graduação em Letras (Área de Concentração: Estudos Literários) da UNESP, Campus de Araraquara, sob orientação da Profa. Dra. Lídia Fachin, tese defendida em 2005.

${ }^{2}$ Universidade Estadual de Londrina - Paraná
} 
pertinência do termo. Como admite Neves (2006, p.18), "muito se tem escrito sobre a caracterização da essência do trágico, mas fica sempre a sensação de que essa essência não pode ser reduzida a simples formulações". De fato, debruçar-se sobre as faces e máscaras do trágico obriga os estudiosos a fazer coro com a pesquisadora, mas a dificuldade de delimitação de uma essência trágica, antes de desestimular, acaba instigando cada vez mais reflexões sobre o fenômeno trágico, em especial sobre sua permanência na literatura moderna e contemporânea.

Qualquer ponderação sobre o assunto leva ao resgate de Aristóteles, principalmente para reforçar uma constatação: o estagirita preocupou-se em descrever uma forma dramática, a tragédia, a partir da qual é possível resgatar o sentido do trágico para os gregos. Sem preocupar-se em "discutir e conceituar propriamente o trágico", Aristóteles "apenas analisa procedimentos e situações que qualifica de trágicos" (MALHADAS, 2003, p. 37); portanto, se quisermos vislumbrar uma conceituação do termo na Poética, temos de nos contentar em investigar os procedimentos de construção da tragédia que permitem sua manifestação. Dessa necessidade deriva uma das contingências do estudo do trágico: por mais que se queira desvinculá-lo da tragédia, esbarra-se sempre no gênero como espaço de sua emergência, ao menos nas origens do gênero. Por outro lado, a constatação da interdependência entre trágico e tragédia não autoriza considerar o primeiro como gênero literário; ao menos para os limites das reflexões propostas neste artigo, o trágico é compreendido como forma de apreensão do mundo, como um modo de percepção da relação entre homem e mundo, podendo, portanto, manifestar-se em qualquer gênero literário e forma dramática ${ }^{3}$.

A tragédia não pode ser compreendida fora do contexto histórico de seu surgimento: o mundo grego do século $\mathrm{V}$ a.C. marcado por uma forte crise de valores. Costa e Remédios destacam que "o aparecimento do pensamento filosófico e a valorização do elemento racional" (COSTA; REMÉDIOS, 1988, p. 7), entre os séculos VIII e VII a.C., favorece a emersão do racionalismo político e estimula certo distanciamento entre a arte grega e os cultos e rituais religiosos. Essas condições históricas favorecem o aparecimento da tragédia, na medida em que há uma ordem mítica agonizante e um mundo racionalista em efervescência; o universo se apresenta, portanto, como "um choque de forças não só opostas mas inconciliáveis. O mundo do trágico pode então ser visto como um debate cujo cerne reside numa ambigüidade." (HELENA, 1983, p. 23).

\footnotetext{
${ }^{3}$ Penso, por exemplo, nas produções agrupadas sob o nome de "teatro do absurdo", cuja tônica é a percepção da dimensão trágica da existência sem que necessariamente se trate de tragédias, ou na presença de um sentimento do trágico em contos, romances ou crônicas.
} 
Vernant destaca que a tragédia perdura por aproximadamente 80 anos, apagandose quando do triunfo da filosofia e constituindo-se "como a expressão de um tipo particular de experiência humana, ligada a condições sociais e psicológicas definidas" (VERNANT, 2002a, p. 8). Entretanto, embora trágico e tragédia devam ser pensados inicialmente em sua historicidade, interessa também compreender como essa forma dramática e esse modo de percepção do mundo atravessam os tempos, chegando ao teatro moderno. Trágico e tragédia, esse binômio indissociável, conquanto tenham surgido num contexto muito particular, permanecem como forças geradoras da criação literária.

Prova de que ambos não perdem sua vitalidade é a presença, no drama moderno, de muitas reescrituras de mitos e novas formulações da tragédia. Minha reflexão sobre o trágico e a tragédia pauta-se pelo estudo de duas reescrituras de um dos mitos mais férteis do imaginário ocidental: a saga de Antígona, a obstinada filha de Édipo. Refiro-me a Antigone (1942) de Jean Anouilh (1910-1987) e a A Antígona de Sófocles (1948) de Bertolt Brecht (1898-1956). Retomada no século XX em pleno contexto da Segunda Guerra Mundial, a heroína sofocliana ganha novos contornos, assim como a estrutura da tragédia é renovada tanto por Anouilh quanto por Brecht por meio de diversos procedimentos, dentre os quais merece destaque o metateatro, seja pela inserção de reflexões críticas sobre drama e tragédia - como faz o autor francês -, seja pelos recursos de distanciamento utilizados por Brecht n' A Antígona de Sófocles.

O teatro moderno, ao resgatar a tragédia, acaba revisitando o sentido do trágico no mundo grego; quando isso é feito por meio do resgate de um mito, estabelece-se um diálogo íntimo entre dois mundos distantes no tempo e no espaço e particularmente marcados por ordens diversas de valores. $\mathrm{O}$ fragmentado mundo moderno não permite mais ao homem o anseio por um cosmos equilibrado, justo e ordenado. Distante do século $V$ a.C. grego, o teatro moderno explora novas possibilidades de emersão do trágico. Passo, então, a analisar como novas faces do trágico surgem na modernidade dramatúrgica a partir das reescrituras do texto sofocliano empreendidas por dramaturgos que procuraram no universo mítico grego uma forma de traduzir as angústias do homem fragilizado pela guerra.

\section{Reescrituras e novas configurações do mito}

O mito de Antígona, tal como foi dramatizado por Sófocles, tem como cenário o palácio dos Labdácidas, na cidade de Tebas. Após a morte dos irmãos Etéocles e Polinices na disputa pelo trono de Tebas, Creonte, irmão de Jocasta e ocupante do trono, ordena que Etéocles, por ter morrido em defesa da cidade, deve ser sepultado com todas 
as honras fúnebres dispensadas aos grandes heróis. Já Polinices, morto em batalha contra Tebas, deve permanecer insepulto, sendo "seu cadáver alimento das aves e dos cães, de modo que olhá-lo cause horror" (SÓFOCLES, 1992, p. 23). Segundo as crenças do mundo grego, a alma cujo corpo permanece insepulto continua a errar sem descanso; em respeito às leis divinas, todo corpo deve receber as libações necessárias, cabendo aos familiares consangüíneos a obrigação religiosa de oferecê-las aos mortos, sepultando seus corpos (ROSENFIELD, 2000, p. 45). Contra o édito real, Antígona defende que as leis divinas, superiores às ordens humanas, devem ser respeitadas.

A posição assumida por Antígona diante do édito desencadeia toda a tragédia. Creonte se mantém resoluto em sua decisão a ponto de condenar a sobrinha, noiva de seu filho Hémon, à morte. Embora seja alertado pelo filho, pelos conselheiros (Coro) e pelo adivinho Tirésias de que sua atitude não agrada aos deuses nem ao povo de Tebas, Creonte ordena que Antígona seja mantida presa em uma caverna, alimentada apenas com pão e água. Quando, enfim, ele volta atrás em sua decisão, já é tarde: Antígona se enforca na prisão; Hémon se mata com uma espada aos pés da noiva; Eurídice, esposa de Creonte, se suicida ao saber da morte do filho. Resta apenas Creonte, arrependido por não ter dado ouvidos à prudência e por ter colocado seu orgulho de governante acima das leis dos deuses.

Para Hegel (1996), o texto sofocliano é a expressão trágica por excelência do choque das duas ordens de valores que instauram a tragédia clássica: a ordem míticoreligiosa, defendida por Antígona, e a ordem da polis cujo representante é Creonte. Segundo Hegel, a ação das personagens trágicas é determinada por "forças universais que regem a vontade humana e se justificam por si mesmas" (HEGEL, 1996, p. 647); dito de outro modo, a grandeza do conflito trágico está na oposição entre forças de igual potência e diametralmente opostas, como é o caso de Antígona e Creonte. Explica Hegel:

[...] Quando essas forças particulares, como exige a poesia dramática, são chamadas a atuar publicamente, realizando-se como fins determinados de uma paixão humana que desencadeia a ação, destrói-se o acordo que existia entre elas e combatem-se mutuamente. A ação individual que visa, em circunstâncias determinadas, realizar um fim ou impor a superioridade de um caráter, adota necessariamente uma atitude de isolamento, levanta contra si a paixão oposta e assim geram inevitáveis conflitos. Em princípio, o lado trágico consiste em que ambas as partes opostas têm igualmente razão, ao passo que na realidade cada uma concebe o verdadeiro conteúdo positivo do seu fim e do seu caráter como uma negação do fim e do caráter adversos e os combate, o que as torna igualmente culpadas" (HEGEL, 1996, p.648). 
A afirmação de Hegel permite pensar que Creonte divide a posição de herói trágico com Antígona, considerando-se que ambos incorrem em desmedida (hybris) e erro de julgamento (hamartia); além disso, se Antígona sacrifica a própria vida a fim de recompor a ordem cósmica, também Creonte sacrifica sua família - inclusive sua possibilidade de descendência no poder... - em defesa de valores que considera justos. Daí ser possível afirmar que o trágico se instaura em função de ambos terem igualmente razão e serem igualmente culpados. Nas reescrituras, esse pressuposto hegeliano de emersão do trágico não se verifica, pois os textos dirigem a empatia do receptor para a figura de Antígona, anulando a possibilidade de se considerar justa a perspectiva de Creonte.

Anouilh e Brecht resgatam o mito de Antígona estimulados pelo mesmo contexto histórico: ambos os autores vivem a Segunda Guerra e traduzem essa experiência esteticamente por meio da reescritura do texto sofocliano; ambos protestam contra a barbárie que toma conta do mundo. Todavia, considerando a condição da França de país invadido, a Antígona de Anouilh pode ser lida como símbolo da resistência à ocupação alemã; já a heroína brechtiana torna-se uma voz de denúncia das arbitrariedades cometidas por Hitler. Vistos conjuntamente, os textos configuram perspectivas complementares acerca de um episódio violento da história ocidental.

Em Antigone, o elemento central do texto sofocliano - a questão religiosa - é suprimido. Embora Antigone declare seu dever de enterrar o irmão, não é essa a verdadeira motivação do gesto. A ação da heroína passa a ser uma questão existencial, quer dizer, se trata agora de definir os limites da ação humana; é uma questão de afirmação da individualidade e da liberdade humanas, posicionamento que aponta marcas da filosofia existencialista sartriana na peça. Créon colabora para que o elemento religioso perca importância quando se refere à hipocrisia e à falta de sentido na prestação dos ritos fúnebres ou quando revela o caráter espúrio dos irmãos de Antigone: Polynice e Étéocle não merecem qualquer sacrifício ou respeito, seja religioso, seja político. Desprovido da tensão entre os valores da religião e os do Estado, o embate entre Antigone e Créon não mais traduz o embate entre ordens de valores desiguais, tal como destaca Jean Sauvenay:

Le drame religieux, mystique, qui donnait à la pièce grecque son ultime signification, n'est plus qu'un point de départ, bientôt dépassé. Au conflit entre la loi divine et la loi humaine se substitue le conflit entre deux lois humaines, deux conceptions de la vie, l'une qui est acceptation, démission, et l'autre refus (refus du bonheur, de l'impureté). Chez Sophocle, trois sortes de raisons poussent Antigone à agir : au plus bas degré, à peine perceptible, la satisfaction qu'on éprouve à se poser en s'opposant; audessus, l'amour fraternel; et enfin la pure charité, le devoir religieux. 
Anouilh a exactement renversé l'ordre de ces raisons. ${ }^{4}$ (SAUVENAY, 1977, p. 34).

O crítico destaca o prazer da oposição, a pulsão de contrariar a ordem estabelecida a fim de impor sua vontade pessoal como a principal motivação da heroína de Anouilh. Diante da ordem social estabelecida, Antigone opta pela transgressão, pela rebeldia, ao passo que Créon se erige defensor dessa mesma ordem. O tio já não é mais o rei autoritário que deseja se impor no poder: é alguém que assume uma função na estrutura social e procura desempenhá-la adequadamente. Créon incorpora o papel do político, do estrategista que deve garantir a ordem a qualquer custo, afastando-se assim do perfil do rei traçado em Sófocles. Além da mudança nas motivações, mudam também os papéis a serem desempenhados pelas personagens. Se Créon defende a estrutura social estabelecida, a Antigone cabe questioná-la; enquanto Créon se esforça para garantir o exercício tranqüilo do governo, Antigone diz "não" e assim desestabiliza o aparentemente sólido mundo burguês.

A atualização do mito proposta por Brecht é um tanto mais radical que a de Anouilh, particularmente pelo acréscimo de um Prelúdio cuja delimitação temporal é abril de 1945 e as personagens são duas irmãs que voltam de um abrigo antiaéreo e encontram na casa vestígios do retorno do irmão que serve ao exército alemão. Elas se alegram, mas em seguida ouvem gritos no pátio e vêem o irmão prestes a ser enforcado por deserção. Instaura-se o dilema: devem elas, arriscando a própria vida, tentar salvar o irmão ou negar conhecê-lo? A contemporaneidade da questão amplifica o recurso tipicamente brechtiano do distanciamento, afinal, a pergunta ecoa na platéia, levando o público inevitavelmente a sentir-se na pele das irmãs, sendo instado a tomar uma posição (política) diante da cena (teatral e histórica).

O desenvolvimento da ação do texto de Brecht segue os mesmos episódios do texto clássico e, tal como em Sófocles, reserva o momento de maior tensão dramática para a cena de confronto entre Antígona e Creonte. Também nessa reescritura a dimensão religiosa do mito é obliterada, agora em favor da ênfase sobre a dimensão política do gesto da heroína. Se em Anouilh ela defende a liberdade individual e denuncia a submissão aos papéis sociais, agora ela delata claramente o abuso de poder de

\footnotetext{
4 "O drama religioso, místico, que dá à peça grega sua significação maior, é apenas um ponto de partida, logo ultrapassado. O conflito entre a lei divina e a lei humana é substituído pelo conflito entre duas leis humanas, duas concepções de vida, uma que é aceitação, renúncia, e outra que é recusa (recusa da felicidade, da impureza). Em Sófocles, três ordens de razões impulsionam Antígona a agir: em última escala, quase imperceptível, a satisfação que se experimenta com o confronto; um pouco acima, o amor fraterno; e enfim, a caridade pura, o dever religioso. Anouilh inverte precisamente a ordem dessas razões.". Tradução minha.
} 
Creonte na condução da guerra; aliás, a guerra, que mal figura no texto sofocliano, passa a ser a tônica do texto brechtiano. Na reescritura, os irmãos não se matam mais pelo trono, pois ambos lutam do mesmo lado, mas Polinices, consciente de que a guerra atende mais a interesses pessoais do que coletivos, decide desertar e é morto pelos próprios companheiros. A mudança de perspectiva, obviamente, cria novos sentidos do mito de Antígona nas reescrituras.

\section{Trágico e tragédia no teatro moderno}

A primeira indagação suscitada pela análise das reescrituras é se esses textos se constituem como tragédias. Gerd Bornheim (1992), a fim de compreender a permanência e a configuração do trágico na dramaturgia moderna, busca resgatar os pressupostos fundamentais da tragédia, que ele resume em dois pontos. O primeiro é a presença de um herói em cuja existência o trágico se manifeste. No caso das reescrituras, a despeito das mudanças de motivações e encadeamento das ações, a configuração da heroína continua a mesma: retidão de caráter, obstinação, autenticidade, defesa de valores que julga corretos. Mudam os contextos e aquilo por que luta Antígona, mas ela permanece disposta a arriscar a própria vida para atingir seus objetivos. Portanto, ambos os textos modernos atendem a essa primeira exigência do gênero.

Em segundo lugar, Bornheim aponta a necessidade de que a ordem de valores em que se insere o herói permita a emergência do trágico. No texto sofocliano, o confronto entre ordens diversas é claro: de um lado as leis humanas, representantes da ordem da pólis; de outro lado as leis divinas, memória da ordem mítica. Na peça de Anouilh, Créon e Antigone colocam-se em posições antagônicas - ela defende a autenticidade, enquanto ele deixa-se render à representação de papéis sociais, curvando-se às exigências e contingências do exercício do poder -, mas ambos estão imersos na mesma ordem de valores burgueses. Antigone não se submete àquilo que a sociedade espera dela, defendendo o "ser" acima do "parecer"; Créon não vê problema algum que, em nome da felicidade burguesa, seja necessário abrir mão de alguns princípios. Brecht também posiciona suas personagens em campos opostos, pois Creonte recorre a qualquer subterfúgio - mentira, manipulação, violência gratuita - para assegurar-se no poder, ao passo que Antígona aplica todas as suas energias no esforço de desmascará-lo, denunciando a arbitrariedade da guerra por ele conduzida; mas também eles pertencem a uma mesma ordem social em que a ganância justifica a violência contra o outro. Inseridos na mesma ordem social, os protagonistas confrontam-se por defenderem posicionamentos diferentes. 
Mesmo não existindo mais duas ordens de valores (universais) conflitantes, um dado novo garante a permanência de traços do trágico nas reescrituras: o mundo em que as personagens se inserem constitui por si só algo conflitante ou no qual um equilíbrio é muito pouco provável. As fraturas da guerra estão presentes ou são ainda muito recentes no momento de produção das reescrituras para que seja possível pensar num mundo unitário e justo. De todo modo, trata-se de uma ordem de valores (sociais) contra a qual o herói tem razões para se insurgir e a qual permite a emergência do trágico, embora de modo e feição diferentes do trágico clássico.

Considerando que Aristóteles explicita que a tragédia não se configura como imitação de homens (caracteres), mas de uma ação, Bornheim afirma que a tragédia se constituiu a partir de uma polaridade: "o homem e o mundo em que ele se insere. No momento em que esses dois pólos, de um modo imediato ou mediato, entram em conflito, temos a ação trágica" (BORNHEIM, 1992, p. 74). Das partes da tragédia, a que melhor explicita esse confronto do homem com o mundo de que faz parte é o agon. Trata-se de

um confronto organizado, no qual se contrapõem dois longos discursos, geralmente seguidos de um intercâmbio de versos, tornando os contrastes mais densos, mais tensos, mais crepitantes. No agon, cada um defendia o seu ponto de vista com toda a força retórica possível, numa grande exposição de argumentos, que naturalmente contribuía para esclarecer seu pensamento, ou sua paixão. (ROMILLY, 1998, p.37).

Em Antigone, Créon trata a transgressão de Antigone como uma questão de administração, como tantas outras que tem para resolver, e procura convencê-la a capitular, negando seu gesto anárquico, apontando-lhe como ele é absurdo. Antigone até compreende os argumentos do tio, mas quando este pergunta se sua atitude tem motivação política, ela desmente. Antigone não age para insuflar uma revolta, nem em nome de outros ou mesmo em memória de seu irmão: tudo que faz é por si mesma, em defesa de sua integridade moral e liberdade individual. Creonte esconde-se atrás dos constrangimentos impostos pelos papéis sociais, mas Antigone afirma "qu'il fallait dire non, alors!" ${ }^{5}$ (ANOUILH, 1994, p.63); todo o poder do rei serve apenas para obrigá-lo a curvar-se às inúmeras incumbências do exercício do poder, mas não lhe garante prerrogativas sobre a vida privada. Livre desses constrangimentos, Antigone pode afrontá-lo - a ele e à ordem social por ele representada:

Qu'est-ce que vous voulez que cela me fasse, à moi, votre politique, votre nécessité, vos pauvres histoires? Moi, je peux dire "non" encore à tout ce

\footnotetext{
5 “então, é necessário dizer 'não'!”. Tradução minha.
} 
que je n'aime pas et je suis seul juge. Et vous, avec votre couronne, avec vos gardes, avec votre attirail, vous pouvez seulement me faire mourir, parce que vous avez dit "oui". ${ }^{6}$ (ANOUILH, 1994, p.63).

Em A Antígona de Sófocles as personagens também tomam posições opostas, embora dentro da mesma ordem social. Antígona sabe que a guerra de Creonte tem por objetivo pilhar o metal de Argos para com ele alimentar a própria guerra. Em se tratando de Brecht, pode-se entrever uma metáfora do modo capitalista de produção no qual a exploração dos trabalhadores serve para alimentar o próprio sistema. Creonte sabe que a guerra está perdida, mas mantém a ilusão de vitória no povo, que festeja inocentemente. Antígona é a única que o afronta, desmascarando suas intenções escusas.

CREONTE - Por que és tão obstinada?

ANTÍGONA - Para servir de exemplo [...]. Das tuas palavras / Nenhuma me agrada e não irá me agradar jamais. / E assim também eu não irei te agradar em nada / Mas, com meu feito, agrado a outros.

CREONTE - Acreditas que existem outros que vêem as coisas como tu?

ANTÍGONA - Eles também têm olhos e também se sentem atingidos. (BRECHT, 1993, p.216).

O que em Anouilh representa uma questão individual de afirmação da liberdade, em Brecht alcança dimensão coletiva, assim como a dimensão política é acentuada. Antígona torna-se a porta-voz do povo.

Retomando a afirmação de Bornheim de que a ação trágica surge do confronto entre homem e mundo, sendo um dos pressupostos da tragédia, pode-se pensar que as reescrituras atendem também a essa exigência do gênero. A heroína de Anouilh, buscando a autenticidade e preservando a liberdade individual, levanta-se contra um mundo marcado por constrangimentos sociais; a de Brecht desconstrói o discurso autoritário do governo a fim de esclarecer as massas, denunciando um mundo cujos fundamentos são a guerra, o abuso de poder e a violência deles decorrentes.

Se a resposta para a primeira indagação é afirmativa - as reescrituras atendem aos pressupostos básicos da tragédia -, responder à segunda indagação não é tarefa fácil. O trágico se manifesta nas reescrituras? Em caso afirmativo, é da mesma natureza do trágico que se configura no texto sofocliano? Não há dúvidas quanto à presença do trágico nas reescrituras, mas agora com outras formas de manifestação, afinal, "na medida em que os dois pólos [homem e mundo] mudam de natureza, se metamorfoseiam, é o próprio sentido do trágico que se transforma." (BORNHEIM, 1992, p.80).

\footnotetext{
6 "Como você quer que sua política, sua necessidade, suas pobres histórias me atinjam? Eu, eu ainda posso dizer 'não' a tudo que amo e posso ser meu próprio juiz. E você, com sua coroa, com seus guardas, com seu aparato real, você pode apenas me fazer morrer porque disse 'sim'..". Tradução minha.
} 
O mundo moderno, marcado por guerra e destruição, leva o homem a uma percepção da fragilidade da ordem cósmica praticamente impensável no contexto grego. A supressão do elemento divino nas reescrituras deixa o homem abandonado à própria sorte, mas também livre para estabelecer suas próprias regras, princípios e valores. Sob influência do existencialismo sartriano, Antigone propõe uma concepção de homem responsável por suas escolhas, das quais não pode escapar; mais do que isso, o homem é a origem das regras sociais na medida em que não há uma instância superior, divina, controlando seus atos. O texto brechtiano carrega marcas evidentes do marxismo, o que contribui para a composição de um novo perfil de homem: um ser historicamente determinado cujo papel é assumir as rédeas da própria existência e da História. Banido o divino, resta em cena o homem, com suas limitações e responsabilidades.

Como o estofo de ambas reescrituras é a Segunda Guerra, provocada pela ação humana no mundo, desaparece a noção de destino como controle exercido sobre o homem por uma instância superior. O homem é senhor de sua própria vontade, não podendo mais contar com uma entidade superior capaz de portar justiça, ordem e equilíbrio. As reescrituras representam um homem confrontado com o absurdo da existência, percebido seja pelos constrangimentos sociais aos quais deve tentar escapar fazendo uso de sua liberdade individual (Anouilh), seja pela arbitrariedade da violência e do uso do poder os quais deve combater politicamente (Brecht).

No teatro moderno "assistimos [...] a uma ação que se desdobra de modo inverso à da tragédia grega. O herói encarna a justiça, destituído de hybris (ou com uma hybris relativa, que decorre simplesmente das exigências da intriga), enquanto o mundo ou a situação objetiva é injusta: inverte-se, pois, a relação trágica" (BORNHEIM, 1992, p.90-1). Portanto, a desmedida do herói na tragédia moderna reveste-se de positividade. Dito de outro modo, no mundo grego, o universo é ordenado e equilibrado e o sujeito incorre em desmedida porque rompe a harmonia cósmica. Já o mundo moderno é caótico e injusto e o sujeito transforma-se em portador da justiça.

\section{Considerações finais}

A despeito das alterações na forma da tragédia e no sentido do trágico, não se pode dizer que ele está banido da experiência humana na modernidade, mas também é difícil sustentar que o sentido do trágico moderno permanece o mesmo dos tempos da tragédia clássica, senão por outros motivos, ao menos porque a própria forma da tragédia altera-se no decorrer do tempo. Mesmo não tratando especificamente do trágico na Poética, Aristóteles aponta, na estrutura da tragédia, os elementos capazes de provocar o 
trágico, dentre os quais destacamos: a) a configuração do herói trágico, sempre obrigado a fazer uma escolha pautada no limitado saber humano (moîra) e por isso sem saber se a escolha é certa ou errada, se redundará em bem ou em mal; b) a ênfase sobre a concentração da ação, a concatenação lógica dos atos e a presença da peripécia mudança repentina da fortuna do herói - como ingredientes necessários à manifestação do trágico; c) o controverso conceito de catarse, que desloca a discussão do eixo da produção para o da recepção da tragédia, assim como obriga a pensar a questão mais em termos de "sentimento" ou "percepção" do trágico do que de conceituação.

Como procuro apontar nas reescrituras, a configuração do herói trágico agora é outra, pois não há mais destino ou elemento divino que interfira na ação da personagem, assim como a peripécia perde a importância atribuída por Aristóteles para provocar o trágico. Contudo, a questão da percepção do trágico continua premente. Algo na experiência concreta do homem moderno o leva a perceber a trajetória das novas Antígonas como algo capaz de despertar o trágico. E se isso não pode ser expresso de um modo mais exato, ao menos é possível dizer que a percepção do mundo como povoado pelo trágico se mantém. Ao analisar La ville parjure ou Le réveil des Érynyes, peça de Hélène Cixous escrita em 1995, Fachin aponta que

Hoje, o sangue derramado não é a causa da Falha trágica, não constitui a mancha, o miasma cuja reparação depende de cada descendente da família. O trágico nos dias de hoje manifesta-se pela miséria e pela injustiça social, pelas guerras, pelo racismo e a exclusão, mas sobretudo pelas epidemias, numa palavra, pela Aids, que constitui por si só um bom pretexto para o racismo [...] (FACHIN, 2005, p.104).

A afirmação acima leva a pensar que se o trágico no teatro clássico é desencadeado pela presença de uma força a qual se pode nomear destino, no teatro moderno ele é provocado pela ação humana; a presença do humano agora oblitera a influência do divino. Dito de outro modo, o homem está sozinho num mundo caótico, cruel, injusto.

Para Vernant (2002), as formas artísticas surgem em contextos específicos. A invenção da tragédia no mundo grego é a expressão de uma consciência trágica e marca o surgimento de um homem trágico. As tragédias clássicas são a expressão de um modo de compreensão do homem e suas relações com o mundo. A isso Vernant chama historicidade. Embora fruto de condições históricas específicas, as formas artísticas ultrapassam seu contexto de produção, adquirindo caráter transistórico. A permanência do gênero trágico através dos séculos demonstra haver filiação entre a criação da 
tragédia e as formas posteriores assumidas pelo gênero. O herói trágico vem à cena grega como um problema a ser discutido, permanecendo em cena na trajetória do teatro ocidental na condição de tema de debate. Ao retomar um mito clássico, os autores modernos podem explorar a universalidade da tragédia a fim de iluminar seu presente histórico. "A tragédia propõe ao espectador uma interrogação de alcance geral sobre a condição humana, seus limites, sua finitude necessária" (VERNANT, 2002, p. 219): essas reflexões dirão respeito ao homem de qualquer tempo, portanto a reescritura reforça a transistoricidade do gênero trágico.

\section{Referências}

ANOUILH, Jean. Antigone. Paris: Didier, La Table Ronde, 1994.

ARISTÓTELES. Poética. Tradução Eudoro de Souza. São Paulo: Ars Poética, 1993. Edição bilíngüe grego-português.

BORNHEIM, Gerd. Breves observações sobre o sentido e a evolução do trágico. In: O sentido e a máscara. 3. ed. São Paulo: Perspectiva, 1992. p. 69-92.

BRECHT, Bertolt. A Antígona de Sófocles. In: . Teatro completo. Tradução Angelika E. Köhnke e Christine Roehrig. Rio de Janeiro: Paz e Terra, 1993. v. 10, p. 191251.

COSTA, Lígia Militz da; REMÉDIOS, Maria Luiza Ritzel. A tragédia: estrutura e história. São Paulo: Ática, 1988.

FACHIN, Lídia. O discurso trágico na virada do milênio. In: FACHIN, Lídia; DEZOTTI, Maria Celeste Consolin (Org.). Em cena o teatro. Araraquara: Laboratório Editorial FCL/UNESP; São Paulo: Cultura Acadêmica, 2005. p. 103-131.

HEGEL, Georg Wilhelm Friedrich. Estética. Tradução Álvaro Ribeiro e Orlando Vitorino. Lisboa: Guimarães Editores, 1996.

HELENA, Lúcia. A tragédia grega. In: Revista Tempo Brasileiro - Teatro Sempre, no. 72, jan.-mar. 1983. Rio de Janeiro: Folha Carioca, 1983. p.20-35.

MALHADAS, Daisi. Tragédia grega: o mito em cena. São Paulo: Ateliê Editorial, 2003. NEVES, Maria Helena de Moura. O teatro grego: a tragédia. In: MORETO, Fúlvia; BARBOSA, Sidney (Org.). Aspectos do teatro ocidental. São Paulo: Editora Unesp, 2006. p. 13-25.

ROMILLY, Jacqueline de. A tragédia grega. Tradução Ivo Martinazzo. Brasília: Ed. UNB, 1998.

ROSENFIELD, Kathrin Holzermayr. Antígona - de Sófocles a Hölderlin: por uma filosofia trágica da literatura. Porto Alegre: L\&PM, 2000.

SAUVENAY, Jean. On n'a jamais si bien trahi Sophocle. In: BEUGNOT, Bernard (Org.). Les critiques de notre temps et Anouilh. Paris: Garnier, 1977. p. 33-5.

SÓFOCLES. Antígona. Tradução, prefácio e notas de Fernando Melro. Lisboa: Editorial Inquérito Limitada, 1992.

VERNANT, Jean-Pierre. O sujeito trágico: historicidade e transistoricidade. In: VERNANT, Jean-Pierre; VIDAL-NAQUET, Pierre. Mito e tragédia na Grécia antiga. 1. reimp. São Paulo: Perspectiva, 2002. p. 211-9.

. Tensões e ambigüidades na tragédia grega. In: VERNANT, Jean-Pierre; VIDALNAQUET, Pierre. Mito e tragédia na Grécia antiga. 1. reimp. São Paulo: Perspectiva, 2002a. p. 7-24. 